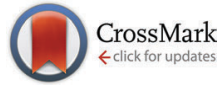

Cite this: Phys. Chem. Chem. Phys., 2014, 16, 23779

\section{ReaxFF reactive molecular dynamics on silicon pentaerythritol tetranitrate crystal validates the mechanism for the colossal sensitivity $\dagger$}

\author{
Tingting Zhou, ${ }^{\text {ab }}$ Lianchi Liu, ${ }^{\text {ac }}$ William A. Goddard III, ${ }^{\text {a }}$ Sergey V. Zybin ${ }^{a}$ and \\ Fenglei Huang ${ }^{d}$
}

\begin{abstract}
Recently quantum mechanical (QM) calculations on a single Si-PETN (silicon-pentaerythritol tetranitrate) molecule were used to explain its colossal sensitivity observed experimentally in terms of a unique Liu carbon-silyl nitro-ester rearrangement $\left(\mathrm{R}_{3} \mathrm{Si}-\mathrm{CH}_{2}-\mathrm{O}-\mathrm{R}_{2} \rightarrow \mathrm{R} 3 \mathrm{Si}-\mathrm{O}-\mathrm{CH}_{2}-\mathrm{R}_{2}\right)$. In this paper we expanded the study of Si-PETN from a single molecule to a bulk system by extending the ReaxFF reactive force field to describe similar $\mathrm{Si}-\mathrm{C}-\mathrm{H}-\mathrm{O}-\mathrm{N}$ systems with parameters optimized to reproduce QM results. The reaction mechanisms and kinetics of thermal decomposition of solid Si-PETN were investigated using ReaxFF reactive molecular dynamics (ReaxFF-RMD) simulations at various temperatures to explore the origin of the high sensitivity. We find that at lower temperatures, the decomposition of Si-PETN is initiated by the Liu carbon-silyl nitro-ester rearrangement forming $\mathrm{Si}-\mathrm{O}$ bonds which is not observed in PETN. As the reaction proceeds, the exothermicity of Si-O bond formation promotes the onset of $\mathrm{NO}_{2}$ formation from $\mathrm{N}-\mathrm{OC}$ bond cleavage which does not occur in PETN. At higher temperatures PETN starts to react by the usual mechanisms of $\mathrm{NO}_{2}$ dissociation and $\mathrm{HONO}$ elimination; however, Si-PETN remains far more reactive. These results validate the predictions from $Q M$ that the significantly increased sensitivity of Si-PETN arises from a unimolecular process involving the unusual Liu rearrangement but not from multi-molecular collisions. It is the very low energy barrier and the high exothermicity of the $\mathrm{Si}-\mathrm{O}$ bond formation providing energy early in the decomposition process that is responsible.
\end{abstract}

Received 22nd August 2014, Accepted 16th September 2014

DOI: $10.1039 / c 4 c p 03781 b$

www.rsc.org/pccp demolition devices, industrial explosives, etc. ${ }^{2,17}$ However, it is quite sensitive to impact, more so than RDX and much more than TNT. Recently, its silicon analogue, silicon-pentaerythritol tetranitrate ( $\left.\mathrm{Si}-\mathrm{PETN}, \mathrm{Si}-\left(\mathrm{CH}_{2}-\mathrm{O}-\mathrm{NO}_{2}\right)_{4}\right)$, was synthesized by the nitration of tetrakis (hydroxymethyl) silane with excess nitric acid $(100 \%)$ in 1,2-dichloroethane at $0{ }^{\circ} \mathrm{C} .{ }^{18}$ Si-PETN has a molecular structure isomorphic with PETN, with the central carbon atom replaced by a silicon atom. Unexpectedly, it exhibits a dramatically enhanced sensitivity, exploding upon every contact with a Teflon spatula, ${ }^{18}$ making it extremely dangerous and difficult to study, particularly by experiments. On one occasion a crystalline material was selected for X-ray diffraction studies, but it exploded under the microscope. Because of its extreme sensitivity, it was characterized only by means of NMR spectroscopy. A significant degree of decomposition of Si-PETN was observed by ${ }^{29} \mathrm{Si}$ NMR spectroscopy after $12 \mathrm{~h}$ of synthesis, showing that the decomposition products of Si-PETN must contain a siloxane feature of the type -OSi- $\left(\mathrm{CH}_{2} \mathrm{OR}\right)_{2} \mathrm{O}-$, which is quite different from its carbon analogue PETN but is fully in agreement with DFT calculations. ${ }^{18}$

To uncover the origin of this highly increased sensitivity of Si-PETN compared to PETN, Klapötke et al. ${ }^{18}$ studied the 
electrostatic potential as well as natural bond orbital of the two compounds using DFT calculations at the B3LYP/6-31G(d) level and concluded that the increased sensitivity of Si-PETN is likely due to the greater tendency to form $\mathrm{Si}-\mathrm{O}$ bonds, compared to the formation of $\mathrm{C}-\mathrm{O}$ bonds in the case of PETN. Then Liu et $a .^{19}$ carried out extensive studies of the unimolecular decomposition reaction pathways for both Si-PETN and PETN by DFT calculations using the unrestricted hybrid functional UB3LYP as well as UM06 at the $6-311 G^{* *}$ level. They examined the reaction energies or activation barriers for five distinct reaction pathways: (1) O- $\mathrm{NO}_{2}$ bond rupture to dissociate $\mathrm{NO}_{2}$; (2) $\mathrm{NO}_{3}$ dissociation; (3) the formation of $\mathrm{CH}_{2} \mathrm{O}$ and $\mathrm{NO}_{2}$; (4) HONO elimination; (5) $\mathrm{Si}-\mathrm{O}$ bond formation. The results indicate that the barrier for $\mathrm{Si}-\mathrm{O}$ bond formation in Si-PETN is $32.0 \mathrm{kcal} \mathrm{mol}^{-1}$, lower than the barriers for other reactions, e.g. the barrier for O-NO $\mathrm{NO}_{2}$ bond rupture in Si-PETN is $35.6 \mathrm{kcal} \mathrm{mol}^{-1}$ and in PETN is $39.0 \mathrm{kcal} \mathrm{mol}^{-1}$, and the barrier for the central $\mathrm{C}-\mathrm{O}$ bond breaking in PETN is $80.1 \mathrm{kcal} \mathrm{mol}^{-1}$. They attributed the colossal sensitivity of Si-PETN to the low barrier and high exothermicity of the rearrangement reaction in which the $\gamma \mathrm{O}$ attacks the central $\mathrm{Si}$ atom, makes a new $\mathrm{Si}-\mathrm{O}$ bond and breaks a $\mathrm{Si}-\mathrm{C}$ bond, a pathway not available to PETN. The transition state of the rearrangement reaction in Si-PETN is formed by bending the $\mathrm{C}-\mathrm{ONO}_{2}$ angle, breaking the partial $\mathrm{Si}-\mathrm{C}$ bond, and making the $\mathrm{Si}-\mathrm{O}$ bond concurrently with a five coordinate $\mathrm{Si}$. The barrier for this Liu carbon-silyl nitro-ester rearrangement is lower than for the normal reactions in PETN: $\mathrm{O}-\mathrm{NO}_{2}$ bond breaking $\left(39.0 \mathrm{kcal} \mathrm{mol}^{-1}\right.$ ) and HONO elimination ( $\left.39.2 \mathrm{kcal} \mathrm{mol}^{-1}\right)$. Furthermore, they found that the overall rearrangement is quite exothermic $\left(45 \mathrm{kcal} \mathrm{mol}^{-1}\right)$, whereas the initial step of PETN (O- $\mathrm{NO}_{2}$ bond dissociation) is endothermic by $39 \mathrm{kcal} \mathrm{mol}^{-1}$. Murray et al. $^{20}$ later investigated computationally why the barrier of the rearrangement is so much lower for Si-PETN than for PETN. Their reaction force analysis found that most of the difference between the rearrangement barriers for the two compounds comes about in the initial stages of the process, in which Si-PETN benefits from a 1,3 electrostatic interaction involving a positive $\sigma$-hole on the silicon and the negative linking oxygen, and the central silicon is more able than carbon to temporarily expand its coordination sphere.

Sensitivity is an extremely important issue for energetic materials (EMs); however, no clear understanding about the molecular and structural determinants controlling their sensitivity to external stimuli has been well established. Although its high instability prohibits its applications in munitions, Si-PETN could provide valuable information about the nature of sensitivity in EMs. Using first-principles DFT with an empirical van der Waals correction, Lin et $a .^{21}$ predicted the stable equilibrium structures and equation of state for Si-PETN. Their results suggest that a phase transition at a much lower pressure than PETN may explain the inherent instability of Si-PETN. To help settle the issue, we consider it would be most useful to understand the atomistic processes involved in thermal decomposition and explosion. Although the quantum mechanics (QM) methods usually applied to the studies of chemical reaction processes are not capable of treating the spatial and time scales involved, we expect that ReaxFF reactive molecular dynamics (ReaxFF-RMD) simulations are in principle well-suited to explore the complicated chemistry behind thermal decomposition and explosion of bulk Si-PETN. This is because similar ReaxFF reactive force fields for other materials have been validated to predict accurately both the reactivity of bonds and mechanical properties of condensed phases. ${ }^{16,22-31}$ The studies of anisotropic sensitivity of PETN and HMX, ${ }^{16,24}$ thermal decomposition of HMX (cyclotetramethylene tetranitramine), TATB (triamino-trinitrobenzene), and RDX, ${ }^{25-27}$ shock dynamics of RDX and PBX (plastic bonded explosives), ${ }^{28-31}$ and so forth using ReaxFF-RMD lead to the results in accordance with available experimental data, making it practical to describe chemical reactions occurring under various conditions during the large scale dynamical processes involving millions of atoms with currently available computational facilities.

To explore the thermal induced chemistry and the reasons for dramatically enhanced sensitivity in Si-PETN, we extended the ReaxFF parameters aiming at providing accurate descriptions of chemical and physical properties for solid Si-PETN. Using ReaxFF-RMD simulations, we can predict crystal structures and simulate changes in bonding associated with the decomposition of Si-PETN and observe the distribution of products formed, gaining insight into how decomposition is initiated and proceeds. By performing simulations at various temperatures, the temperature-dependent reaction rates can be determined, allowing us to directly calculate kinetic parameters for the Si-PETN decomposition process. The rest of this paper is organized as follows: Section 2 describes computational methods; force field training results are provided in Section 3.1 followed by several validation tests in Section 3.2, and thermal decomposition mechanisms are given in Section 3.3; and conclusions are drawn in Section 4 . We consider that these simulations are critical to understand the initial decomposition mechanisms in solid Si-PETN and its colossal sensitivity.

\section{Computational methodology}

\subsection{The ReaxFF reactive force field}

On the basis of the bond order/bond distance relationship, ${ }^{32,33}$ ReaxFF $^{22,23}$ allows for an accurate description of bond breaking and bond formation, including a smooth transition from nonbonded to bonded systems. The connectivity-dependent interactions such as valence angles and torsion angles are also bond order-dependent so that their energy contributions disappear upon bond dissociation. Since the bond orders are updated every iteration, the connectivity of the system can continuously change. Furthermore, ReaxFF incorporates nonbonded (van der Waals and Coulombic) interactions between every atom pair regardless of connectivity, with the repulsion of atoms at close range being avoided by shielding and the long-range attraction supplemented by low gradient correction. Additional potential energy corrections to properly describe bond dissociation and formation in different chemical environments are also considered.

The potential functions used in this application of ReaxFF are shown in eqn (1), which are the same as those reported recently: ${ }^{34}$

$$
\begin{aligned}
E_{\text {total }}= & E_{\text {bond }}+E_{\mathrm{lp}}+E_{\text {over }}+E_{\text {under }}+E_{\mathrm{val}}+E_{\text {pen }}+E_{\text {coa }}+E_{\text {tors }} \\
& +E_{\text {conj }}+E_{\text {H-bond }}+E_{\mathrm{vdw}}+E_{\text {coulomb }}+E_{\mathrm{lg}}
\end{aligned}
$$


where $E_{\mathrm{lp}}$ corresponds to the lone pair energy penalty based on the number of lone pairs around an atom, $E_{\text {over }}$ to the energy penalty for overcoordinated atoms, $E_{\text {under }}$ to the energy contribution for the resonance of the $\pi$-electron between attached undercoordinated atomic centers, $E_{\text {pen }}$ to the energy penalty needed to reproduce the stability of systems with double bonds sharing an atom in a valence angle, $E_{\text {coa }}$ to the three-body conjugation term to describe the stability of $-\mathrm{NO}_{2}$ groups, $E_{\text {conj }}$ to the contribution of conjugation effects to molecular energy, and $E_{\mathrm{lg}}$ to the contribution of long range London dispersion.

ReaxFF reactive force field coupled with the molecular dynamics method provides nearly the accuracy of the best QM but at a computational cost of solving Newton's equation of motion on nuclei only, making it practical to simulate complicated processes with large size and long time scale.

\subsection{Quantum mechanics calculations}

We developed the Si-PETN ReaxFF force field to accurately reproduce the first-principles QM interactions in $\mathrm{Si}-\mathrm{C}-\mathrm{H}-\mathrm{N}-\mathrm{O}$ systems and to provide a way to extend the first-principles accuracy to much larger length and time scales needed to examine the processes of interest here. The training set was extended by adding QM data for systems relevant to Si-PETN chemistry to the ReaxFF training set for energetic materials ${ }^{34}(\mathrm{C}-\mathrm{H}-\mathrm{O}-\mathrm{N}$ interactions) combined with that for $\mathrm{PDMS}^{35}$ ( $\mathrm{Si}-\mathrm{C}-\mathrm{O}-\mathrm{H}$ interactions). These include $\mathrm{Si}-\mathrm{N}$ in $\mathrm{H}_{2} \mathrm{NSiH}_{3}$ and the $\mathrm{Si}=\mathrm{N}$ in $\mathrm{HN}=\mathrm{SiH}_{2}$ scanned to represent silicon-nitrogen bond energy and dissociation pathways, $\mathrm{Si}-\mathrm{O}-\mathrm{N}$ in $\mathrm{H}_{3} \mathrm{SiONH}_{2}$ scanned to represent $\mathrm{Si}-\mathrm{O}-\mathrm{N}$ angle bending energy, as well as reaction pathways for the Si-PETN molecule. QM data were derived from DFT calculations

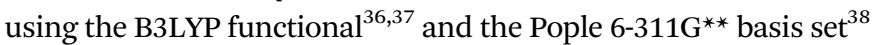
as implemented in the Jaguar 7.5 program package. ${ }^{39}$ The complete QM-derived training set includes atomic bond energy curves, dissociation energies, angle bending energy curves, charge distributions, equation of state, and other relevant material properties, such as heats of formation, energies for molecules with under- and over-coordinated atoms, reaction pathways, and others, for all possible interactions among Si, C, H, O, and N.

\subsection{Reactive molecular dynamics simulations}

$\mathrm{X}$-ray diffraction measurements determined that the space group of the PETN crystal under ambient conditions is $P 42_{1} C$ with the $S_{4}$ molecular point group. ${ }^{4,40}$ Experimental and DFT calculations also predicted that the PETN molecule has $S_{4}$ symmetry in the crystalline phase under ambient conditions. ${ }^{13,14}$ PETN has been found experimentally to have three crystalline phases ${ }^{5,40,41}$ where the most stable PETN-I has crystal symmetry $P 42{ }_{1} c$ with two formula units per unit cell. ${ }^{41}$ The crystal structure data for Si-PETN are unavailable experimentally due to its extreme instability. By replacing the central carbon atom of PETN by silicon, Lin et $a .^{21}$ relaxed three different types of Si-PETN crystal structures by DFT calculations and found that the most stable structure is Si-PETN-I $\left(P 42_{1} c\right.$ space group, $S_{4}$ molecule symmetry). Hence, the Si-PETN crystal with $P 42{ }_{1} c$ space group and $S_{4}$ molecule symmetry served as the basic structure for the calculations reported here.
The developed force field was validated by predicting molecular and crystal structures of Si-PETN. We replaced the central carbon atom of PETN with a silicon atom without changing the Cartesian atomic coordinates to prepare the initial Si-PETN structure. The optimized molecular structure was obtained by energy minimization using the Shanno conjugate gradient method. ${ }^{42}$ The procedure to predict crystal structure by ReaxFF involved minimization of a $2 \times 2 \times 3$ supercell including 696 atoms to optimize the atomic positions as well as cell parameters followed by isothermal-isobaric molecular dynamics (NPT-MD) simulations at atmospheric pressure to relax internal stresses. Two temperatures were initiated using a Maxwell Boltzmann distribution of velocities at 5 and $300 \mathrm{~K}$. Here, we used the Nose-Hoover thermostat (100 fs damping constant) and the Rahman Parrinello barostat (1000 fs damping constant) to control temperature and pressure, respectively. The NPT-MD simulations were performed for $40 \mathrm{ps}$ with the last 20 ps used for statistical calculation of equilibrium lattice parameters. A time step of 0.2 fs was employed in these simulations.

The equilibrium crystal structure at $300 \mathrm{~K}$ was then used as the initial structure to investigate the thermal decomposition mechanisms and kinetics of bulk Si-PETN at six temperatures: 1000, 1200, $1400,1600,1800$, and $2000 \mathrm{~K}$. The material was quickly heated from $300 \mathrm{~K}$ to target temperatures (e.g. the system was heated from $300 \mathrm{~K}$ to $1600 \mathrm{~K}$ in $0.1 \mathrm{ps}$ ) using a canonical (NVT) ensemble prior to observing any reactive events. Thereafter, molecular dynamics simulations with the NVT ensemble were performed at these target temperatures for at least 20 picoseconds. To consider the influence of an increase in temperature on decomposition mechanisms and kinetics due to energy release from exothermal reactions, additional RMD simulations were carried out using a microcanonical (NVE) ensemble at the initial temperatures of 1200, 1400, 1600 and $1800 \mathrm{~K}$ for at least 100 picoseconds. The time step in these RMD simulations of thermal decomposition was set to 0.1 fs to describe correctly the high-temperature, thermally induced chemical reactions under homogeneous conditions. The results from these simulations were used to investigate the kinetics of decomposition and product distributions as a function of temperature. The algorithm of molecule recognition in the product analysis uses the connection table and bond orders calculated by ReaxFF at each step and records the molecular components and their compositions every $50 \mathrm{fs}$. In this analysis, appropriate bond-order cutoffs for each pair of atoms were used to identify molecular species in the systems, which are tabulated in Table S1 of the ESI. $\dagger$ The bondorder cutoffs do not affect the simulations but only the interpretation in terms of chemical components.

All MD simulations were performed using the "Large-scale Atomic/Molecular Massively Parallel Simulator" (LAMMPS) ${ }^{43}$ molecular dynamics program from Sandia National Laboratories.

\section{Results and discussion}

\subsection{Development of the ReaxFF force field}

We started with recently derived ReaxFF parameters for $\mathrm{C} / \mathrm{H} / \mathrm{N} / \mathrm{O}$ from ref. 35 and $\mathrm{Si} / \mathrm{C} / \mathrm{O} / \mathrm{H}$ from ref. 36 and then optimized these 
parameters to minimize the differences between QM and ReaxFF results. These optimized parameters are available in a "ffield" file in the ESI. $\dagger$ The results of fitting with respect to the original $\mathrm{C} / \mathrm{H} / \mathrm{O} / \mathrm{N}$ training set are consistent with the published values, ${ }^{34}$ while the results with respect to $\mathrm{Si} / \mathrm{C} / \mathrm{O} / \mathrm{H}$ are not quite the same since the parameters for $\mathrm{Si} / \mathrm{C} / \mathrm{O} / \mathrm{H}$ were obtained using a different potential function $^{35}$ that does not include the extra inner wall ${ }^{44}$ exponential and the low gradient ${ }^{34}$ long-range van der Waals attraction. Here, only the new results for the systems relevant to Si-PETN are presented.

To obtain the silicon nitrogen bond energy, we used the dissociation pathway for the $\mathrm{Si}-\mathrm{N}$ single bond in $\mathrm{H}_{2} \mathrm{NSiH}_{3}$ and the $\mathrm{Si}=\mathrm{N}$ double bond in $\mathrm{HN}=\mathrm{SiH}_{2}$. In performing DFT calculations, we determined ground-state structures through full geometry optimizations. Then, dissociation profiles were calculated by constraining only the bond length of interest and re-optimization of the remaining internal coordinates. To optimize the ReaxFF parameters, the DFT results for the singlet case were used around the equilibrium bond distance while the dissociation limit was fitted against the DFT results for the triplet state. The trends in ReaxFF dissociation energy as well as equilibrium bond distance for $\mathrm{Si}-\mathrm{C} / \mathrm{Si}-\mathrm{O} / \mathrm{Si}-\mathrm{N}$ are in good agreement with the QM data as shown in Fig. S1 of the ESI. $\dagger$

The valence angle parameters were optimized to represent angle bending energies from DFT calculations on various molecules. For each case, the geometry of the representative molecule was optimized with the angles of interest fixed to obtain angle bending energies relative to the optimal geometry. These include various molecules in the training set to cover possible $\mathrm{Si} / \mathrm{N} / \mathrm{C} / \mathrm{O} / \mathrm{H}$ valence angle combinations, such as $\mathrm{Si}-\mathrm{O}-\mathrm{N}, \mathrm{C}-\mathrm{Si}-\mathrm{C}, \mathrm{Si}-\mathrm{Si}-\mathrm{C}$, $\mathrm{Si}-\mathrm{C}-\mathrm{Si}, \mathrm{O}-\mathrm{C}-\mathrm{Si}, \mathrm{Si}-\mathrm{O}-\mathrm{C}, \mathrm{O}-\mathrm{Si}-\mathrm{C}$, etc. The results for the four typical angles $\mathrm{C}-\mathrm{Si}-\mathrm{C}, \mathrm{Si}-\mathrm{O}-\mathrm{C}, \mathrm{Si}-\mathrm{O}-\mathrm{N}$, and $\mathrm{O}-\mathrm{Si}-\mathrm{C}$ presenting in Si-PETN from ReaxFF are in reasonable agreement with those from QM calculations (see Fig. S2 of the ESI $\dagger$ ). The parameters related to the torsion angle were also optimized to better describe the molecular structure of Si-PETN, in particular the dihedrals like $\mathrm{Si}-\mathrm{C}-\mathrm{O}-\mathrm{N}$ and $\mathrm{C}-\mathrm{Si}-\mathrm{C}-\mathrm{O}$ that are easy to be distorted.

Liu et al. ${ }^{19}$ examined the reaction energies or activation barriers for five distinct reaction pathways related to the decomposition of gas phase Si-PETN by QM calculations, which were added to the training set of this force field. The obtained energies from ReaxFF along with those from QM are collected in Table 1. Although there are some differences in these

Table 1 Comparison of reaction energies in gas phase Si-PETN from ReaxFF and QM

\begin{tabular}{lcc}
\hline Reaction & ReaxFF $\left(\mathrm{kcal} \mathrm{mol}^{-1}\right)$ & $\mathrm{QM}^{a}\left(\mathrm{kcal} \mathrm{mol}^{-1}\right)$ \\
\hline $\mathrm{NO}_{2}$ & 39.89 & 35.6 \\
$\mathrm{NO}_{3}$ & 62.47 & 77.6 \\
{$\left[\mathrm{CH}_{2} \mathrm{O}+\mathrm{NO}_{2}\right](\mathrm{TS})$} & 52.66 & 48.2 \\
$\mathrm{CH}_{2} \mathrm{O}+\mathrm{NO}_{2}$ & 42.57 & 42.3 \\
$\mathrm{HONO}$ (TS) & 53.35 & 39.4 \\
$\mathrm{HONO}$ & -4.21 & -15.4 \\
$\mathrm{Si}-\mathrm{O}$ (TS) & 22.83 & 32.0 \\
$\mathrm{Si}-\mathrm{O}$ & -60.96 & -40.5 \\
${ }$ From ref. 19. & & \\
& &
\end{tabular}

energies from the two methods, the relative positions of these reactions in ReaxFF are consistent with QM results. Thus the initial reaction mechanism favors $\mathrm{Si}-\mathrm{O}$ bond formation compared to $\mathrm{O}-\mathrm{NO}_{2}$ bond cleavage.

\subsection{Molecular and crystal structures of Si-PETN}

11 low energy conformers with various symmetries have been suggested for the PETN molecule by DFT calculations. ${ }^{14}$ Using the same Cartesian atomic coordinates and replacing the central carbon atom by silicon, we employed both the QM method (B3LYP/6-311G**) and the ReaxFF force field to optimize these structures and to compare their stabilities. As shown in Fig. 1, the optimized structures from ReaxFF agree well with those from QM, with the RMSD for all conformers smaller than $0.96 \AA$, validating that the ReaxFF force field describes well the Si-PETN molecular structures. Additionally, the molecule with $S_{4}$ symmetry has the lowest energy from both QM and ReaxFF calculations. Critical bonds, angles, as well as torsions presenting in this structure are summarized in Table 2, showing excellent consistency in the results from QM and ReaxFF. We did not include the 10 higher energy conformers in optimizing ReaxFF parameters since our focus was on the exploration of the reasons for the high sensitivity rather than molecular conformation transformation.

The equilibrated Si-PETN crystal structure at $5 \mathrm{~K}$ obtained by NPT-MD simulation is presented in Fig. 2(a) and the lattice parameters are listed in Table 3 in comparison with those from DFT calculations. Si-PETN has a larger unit cell volume than PETN, 13\%, which is slightly higher than the DFT result. ${ }^{21}$ For PETN, ReaxFF-lg underestimates the $a(b)$ axis and overestimates the $c$ axis leading to a volume expansion of $0.89 \% .{ }^{34} \mathrm{~A}$ similar error likely happens for Si-PETN since the $\mathrm{C} / \mathrm{H} / \mathrm{O} / \mathrm{N}$ parameters in this force field are the same as those in ref. 34 . The only previous prediction for Si-PETN crystal structure ${ }^{21}$ included in Table 3 was a DFT-PBE-v calculation with empirical van der Waals correction ${ }^{45}$ at zero temperature. The ReaxFF leads to an $a(b)$ axis dimension which is $0.09 \AA$ lower while the $c$ axis dimension is $0.18 \AA$ higher than those predicted by PBE-v, but the volumes differ by only $0.63 \%$. For $\mathrm{H}, \mathrm{C}, \mathrm{N}, \mathrm{O}, \mathrm{F}, \mathrm{Cl}$, and $\mathrm{S}$ systems, the DFT-PBE-v calculations yield an average unit cell deformation of $3.2 \%$ and underestimate the unit cell volume by $1 \% .{ }^{45}$ For $\mathrm{Si}$, this error might be larger since no empirical vdW correction is available; ${ }^{45}$ thus the accuracy of the PBE-v results could not be well evaluated.

\subsection{Thermal-induced chemistry for Si-PETN}

3.3.1 NVT-RMD simulations. The time evolution of the initial products per single Si-PETN molecule formed during the thermal decomposition process at temperatures of 1000 and $1200 \mathrm{~K}$ is plotted in Fig. 3(a) and (b). It reveals that the dominant initial reaction pathway at these lower temperatures is the formation of $\mathrm{Si}-\mathrm{O}$ bonds followed by $\mathrm{O}-\mathrm{NO}_{2}$ bond rupture to form $\mathrm{NO}_{2}$ fragments. The $\mathrm{Si}-\mathrm{O}$ bond forms at $4 \mathrm{ps}$ and 3 ps for $T=1000$ and $1200 \mathrm{~K}$, respectively, with the population increasing continuously as the decomposition proceeds. $\mathrm{NO}_{2}$ turns out at $29 \mathrm{ps}$ for $T=1000 \mathrm{~K}$ and it appears at 


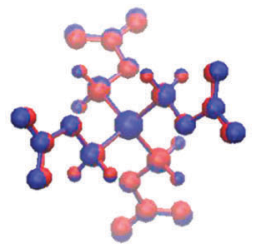

$\mathrm{S} 4 \mathrm{RMSD}=0.554$

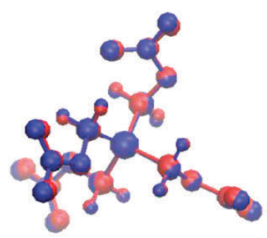

$\mathrm{Cl}(\theta) \mathrm{RMSD}=0.646$

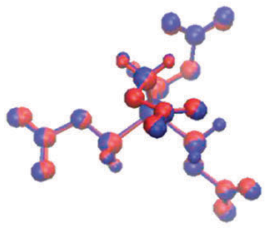

$\mathrm{Cl}(\gamma) \mathrm{RMSD}=0.618$

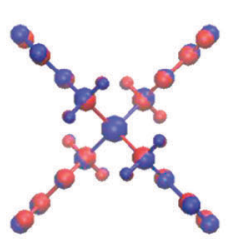

D2 RMSD $=0.739$

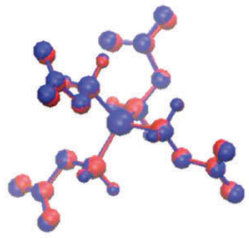

$\mathrm{C} 1(\alpha) \operatorname{RMSD}=0.653$

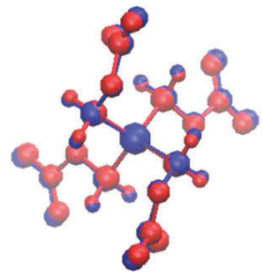

$\mathrm{C} 2(\alpha) \mathrm{RMSD}=0.761$

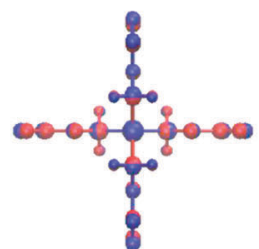

D2d RMSD $=0.763$

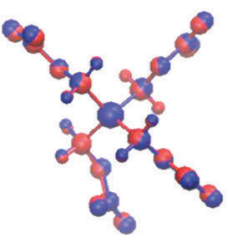

$\mathrm{Cl}(\epsilon) \mathrm{RMSD}=0.613$

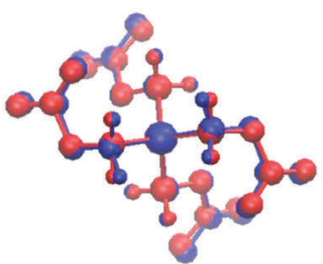

$\mathrm{C} 2(\beta) \mathrm{RMSD}=0.959$

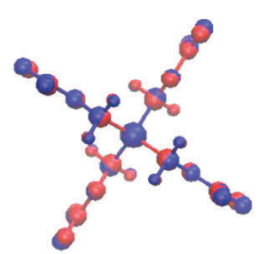

$\mathrm{Cl}(\beta) \mathrm{RMSD}=0.753$

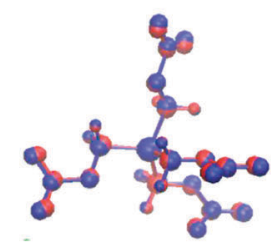

$\mathrm{Cl}(\delta) \mathrm{RMSD}=0.612$

Fig. 1 Comparison of the molecular structures for the 11 Si-PETN conformers with various symmetries from ReaxFF (blue) and QM (red). Only the $S_{4}$ case was used in training.

Table 2 Comparison of critical bonds, angles, and torsions for the Si-PETN molecule with $S_{4}$ symmetry from ReaxFF and QM

\begin{tabular}{lllllllr}
\hline Bond & QM $(\AA)$ & ReaxFF $(\AA)$ & Angle & QM $\left(^{\circ}\right)$ & ReaxFF $\left({ }^{\circ}\right)$ & Torsion & QM $\left(^{\circ}\right)$ \\
\hline Si-C & 1.901 & 1.943 & C-Si-C & 109.033 & 106.526 & Si-C-O-N & -178.750 \\
C-O & 1.437 & 1.406 & Si-C-O & 104.380 & 101.092 & O-C-Si-C & -56.934 \\
O-N & 1.457 & 1.480 & C-O-N & 114.171 & 113.920 & C-Si-C-O & 177.475
\end{tabular}
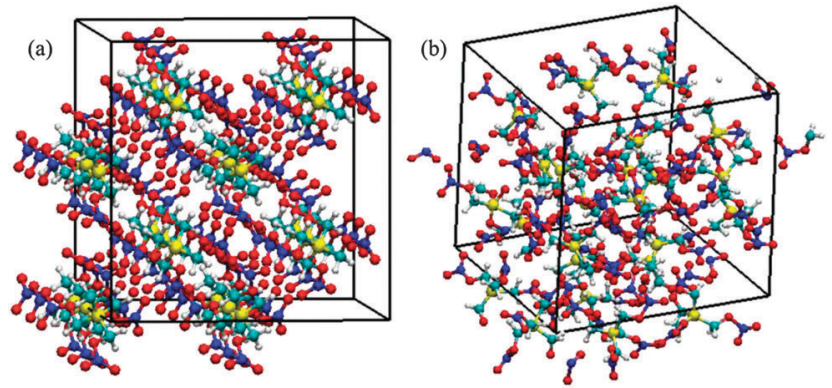

Fig. 2 Crystal structures of Si-PETN predicted by ReaxFF. (a) At $5 \mathrm{~K}$ after 40 ps NPT-MD simulation; (b) at $1200 \mathrm{~K}$ after 100 ps NVT-RMD simulation, where the formation of $\mathrm{Si}-\mathrm{O}$ bonds is clearly observed.

Table 3 Unit cell lattice parameters for Si-PETN from ReaxFF at 5 and $300 \mathrm{~K}$ and at atmospheric pressure

\begin{tabular}{lccc}
\hline & & \multicolumn{3}{c}{ ReaxFF } \\
\cline { 3 - 4 } Cell parameters & DFT $^{a}$ & $T=5 \mathrm{~K}$ & $T=300 \mathrm{~K}$ \\
\hline$V\left(\AA^{3}\right)$ & 632.6 & 636.6 & 657.6 \\
$a(\AA)$ & 9.71 & 9.62 & 9.73 \\
$b(\AA)$ & 9.71 & 9.62 & 9.73 \\
$c(\AA)$ & 6.71 & 6.89 & 6.96
\end{tabular}

${ }^{a}$ From ref. 21. about 8 ps with an obvious rise after 38 ps for $T=1200 \mathrm{~K}$. It is quite clear that the formation of $\mathrm{Si}-\mathrm{O}$ bonds is much faster than $\mathrm{O}-\mathrm{NO}_{2}$ bond fission, leading to more $\mathrm{Si}-\mathrm{O}$ bonds generated in a shorter time. These results indicate that the thermal decomposition of Si-PETN is more likely to be initiated by $\mathrm{Si}-\mathrm{O}$ bond formation rather than regular $\mathrm{O}-\mathrm{NO}_{2}$ bond breaking due to its lower energy barrier. For $T=1200 \mathrm{~K}, \mathrm{Si}-\mathrm{C}$ bond breaking coupled with $\mathrm{N}-\mathrm{O}$ bond cleavage to form $\mathrm{CH}_{2} \mathrm{O}$ plus $\mathrm{NO}_{2}$ occurs subsequently, and HONO elimination as well as NO splitting off is also observed later.

For the analogous studies on PETN, $\mathrm{NO}_{2}$ and $\mathrm{HONO}$ are the only two products observed on the time scale of our simulations for $T=1200 \mathrm{~K}$. The evolution of these products shown in Fig. 3(c) and (d) demonstrates that the cleavage of the $\mathrm{O}-\mathrm{NO}_{2}$ bond dominates the initial steps of PETN decomposition, which is different from that of Si-PETN. 0.1875 $\mathrm{NO}_{2}$ and 0.0625 HONO per single PETN molecule are observed at 100 ps, which are 1.56 and 2 times less than those for Si-PETN. At $1000 \mathrm{~K}$, no reaction is detected by the end of our simulation (100 ps), illustrating lower sensitivity for this material in comparison with Si-PETN. As expected no analog to the Si-O-C Liu type rearrangement is found in the thermal decomposition of PETN because of its extremely high energy barrier ( $80.1 \mathrm{kcal} \mathrm{mol}^{-1}$ (ref. 19)) as the formation of a five coordinate transition state is very unfavorable 

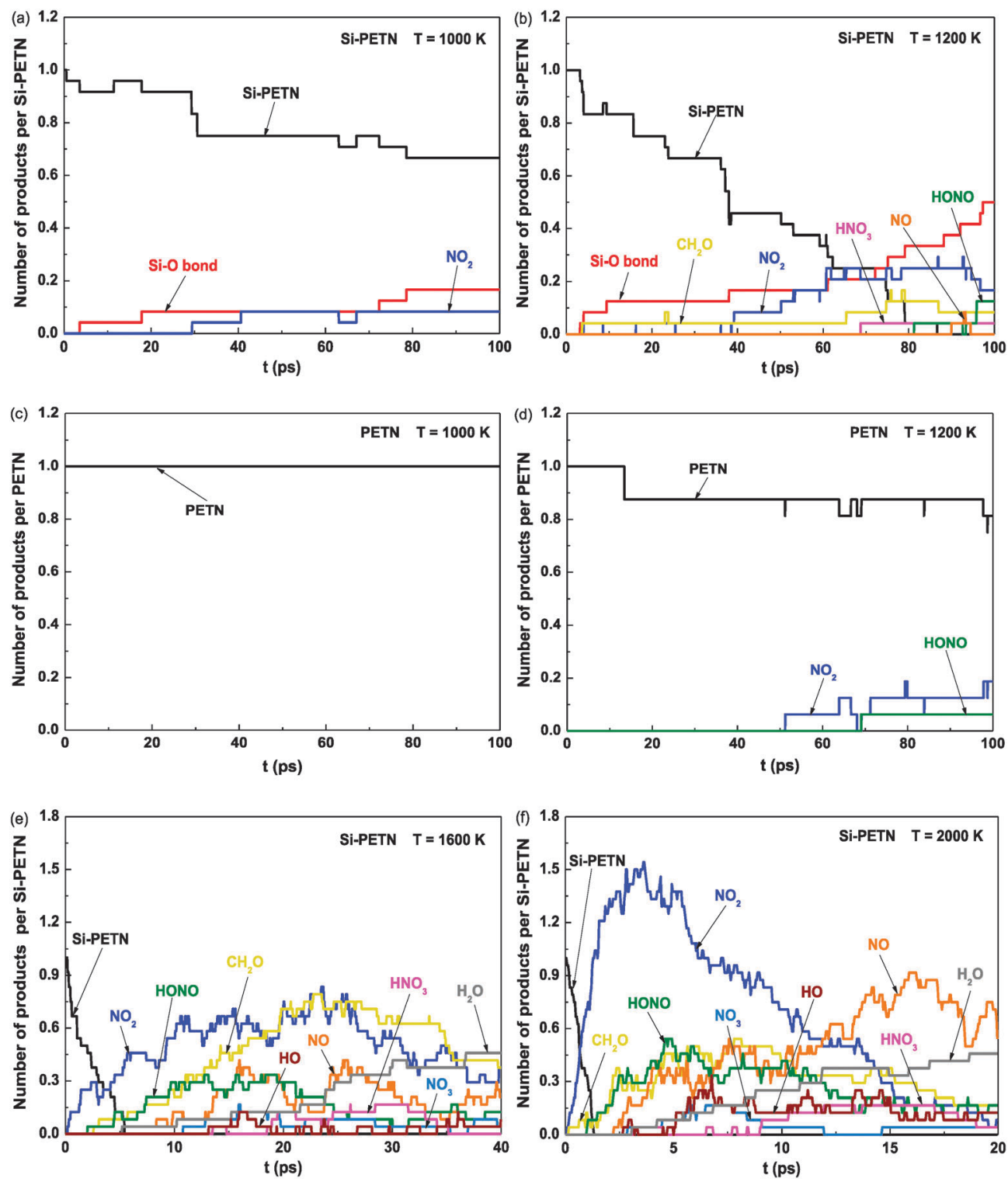

Fig. 3 Time evolution of products during NVT-RMD simulations of Si-PETN and PETN at various temperatures. The decomposition of Si-PETN is initiated by $\mathrm{Si}-\mathrm{O}$ bond formation at lower temperatures.

for carbon compared with silicon. Therefore, these investigations at lower temperatures uncover clearly that the main difference of the initial decomposition mechanisms between condensed Si-PETN and PETN is the Liu carbon-silyl nitro-ester rearrangement in Si-PETN. This leads to the formation of $\mathrm{Si}-\mathrm{O}$ bonds accompanied by a large energy release, promoting $\mathrm{O}-\mathrm{NO}_{2}$ bond breaking as well as other reactions, making Si-PETN much more sensitive than PETN.

Decomposition becomes more active with increasing temperature. Fig. 3(e) and (f) and 4 exhibit the detailed species evolution at 1600 and $2000 \mathrm{~K}$ (for clarity, only components with relatively high abundance are shown), where we see that the decomposition process can be partitioned into two stages:

The initial stage includes the following reaction pathways:

(1) The Liu carbon-silyl nitro-ester rearrangement to form a new $\mathrm{Si}-\mathrm{O}$ bond while retaining the $\mathrm{CO}$ bond,
(2) $\mathrm{NO}_{2}$ dissociation due to $\mathrm{O}-\mathrm{NO}_{2}$ bond rupture,

(3) $\mathrm{CH}_{2} \mathrm{O}$ formation from $\mathrm{Si}-\mathrm{C}$ bond breaking accompanied by $\mathrm{O}-\mathrm{NO}_{2}$ bond cleavage, and

(4) HONO elimination via the hydrogen transfer to $-\mathrm{NO}_{2}$.

The second exothermic stage has reactions involving the generation of intermediates and final products, such as NO, $\mathrm{NO}_{3}, \mathrm{HO}, \mathrm{HNO}_{3}, \mathrm{H}_{2} \mathrm{O}$, etc.

$\mathrm{Si}-\mathrm{O}$ bond formation and $\mathrm{NO}_{2}$ dissociation are found to be the predominant initial reaction pathways followed by $\mathrm{CH}_{2} \mathrm{O}$ and HONO elimination, the population of which increase significantly at elevated temperatures. No significant $\mathrm{NO}_{3}$ formation is observed, which is expected because of the high dissociation energy for the $\mathrm{CH}_{2}-\mathrm{ONO}_{2}$ bond. The quantities of these initial products decline quickly at later times due to secondary reactions that lead to quick consumption of these molecules and fast production of intermediates as well as stable reaction species, such as $\mathrm{HO}, \mathrm{NO}, \mathrm{H}_{2} \mathrm{O}$, etc. 

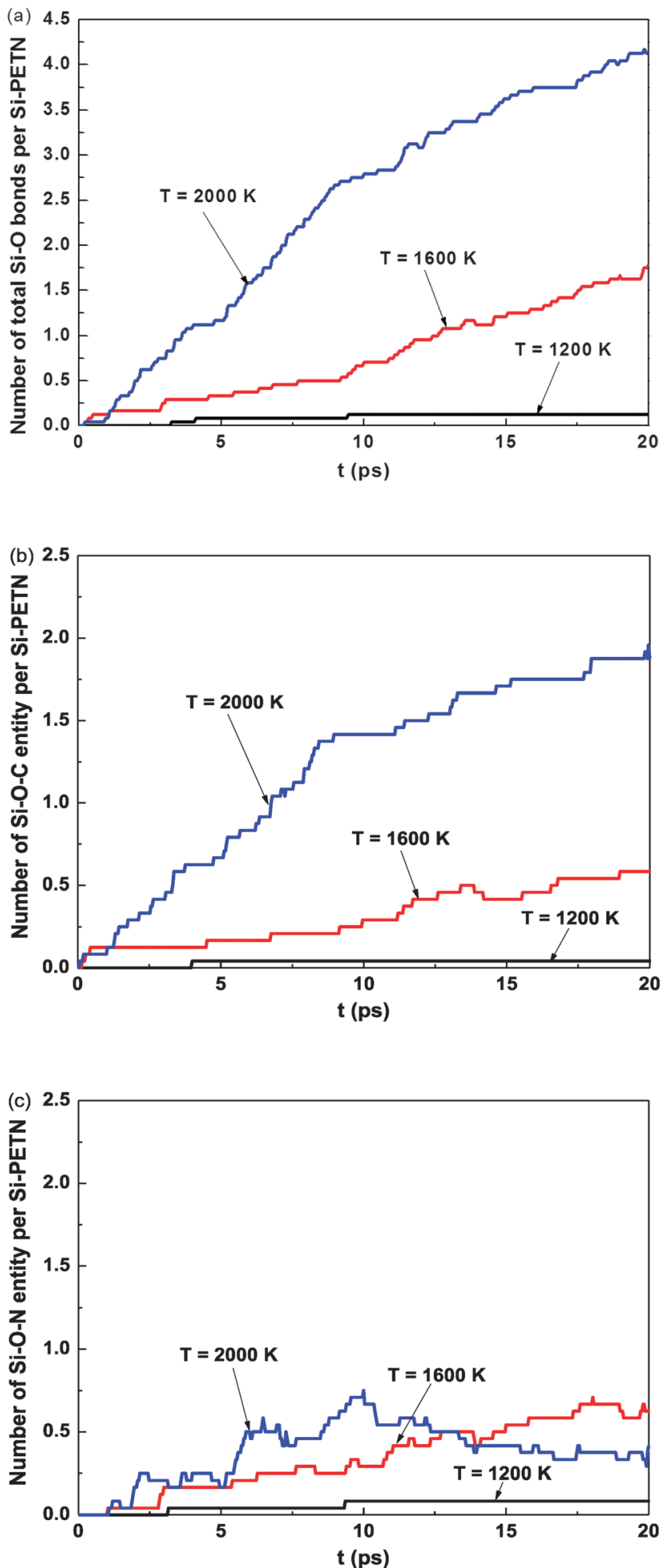

Fig. 4 Time evolution of products formed due to $\mathrm{Si}-\mathrm{C}-\mathrm{O}$ rearrangement during NVT-RMD simulations of Si-PETN at 1200, 1600, and 2000 K. Such rearrangement was not observed during the thermal decomposition of PETN.

Evolution of $\mathrm{Si}-\mathrm{O}$ bonds arisen from the Liu rearrangement plotted in Fig. 4(a) shows that this rearrangement starts early with the number of $\mathrm{Si}-\mathrm{O}$ bonds increasing monotonically on the time scale of our simulations. The rate of $\mathrm{Si}-\mathrm{O}$ bond formation rises rapidly with the increase in temperature, the number of which approaches about 1.25 and 4.125 per single Si-PETN molecule for $T=1600$ and $2000 \mathrm{~K}$, respectively. It manifests that a few silicon atoms form 5 or even $6 \mathrm{Si}-\mathrm{O}$ bonds, e.g. $16.67 \%$ silicon atom forms $5 \mathrm{Si}-\mathrm{O}$ bonds and $4.17 \%$ forms 6 $\mathrm{Si}-\mathrm{O}$ bonds after $20 \mathrm{ps}$ simulation at $2000 \mathrm{~K}$. The Liu rearrangement of Si-PETN leads to the formation of $\mathrm{Si}-\mathrm{O}-\mathrm{CH}_{2}-\mathrm{O}-\mathrm{NO}$, which subsequently decomposes to $\mathrm{Si}-\mathrm{O}-\mathrm{CH}_{2}$ and $\mathrm{NO}_{2}$ or $\mathrm{Si}-\mathrm{O}-\mathrm{NO}$ and $\mathrm{CH}_{2} \mathrm{O}$. Indeed, we see both $\mathrm{Si}-\mathrm{O}-\mathrm{C}$ and $\mathrm{Si}-\mathrm{O}-\mathrm{N}$ entities, the populations of which as functions of time and temperature are presented in Fig. 4(b) and (c). It is clearly seen that the time evolution for $\mathrm{Si}-\mathrm{O}-\mathrm{C}$ and $\mathrm{Si}-\mathrm{O}-\mathrm{N}$ is almost the same for $T \leq 1600 \mathrm{~K}$ : the quantities of the two entities rise monotonously with the increase in temperature and duration. For $T=2000 \mathrm{~K}$, the number of $\mathrm{Si}-\mathrm{O}-\mathrm{N}$ entities goes down gradually after reaching the maximum at 9.8 ps due to secondary reactions that consume the reactant, whereas the population of Si-O-C entities goes up at a higher rate from the beginning to the end to reach a stable value. These results indicate that the decomposition of $\mathrm{Si}-\mathrm{O}-\mathrm{CH}_{2}-\mathrm{O}-\mathrm{NO}$ is likely to form $\mathrm{Si}-\mathrm{O}-\mathrm{C}$ and $\mathrm{Si}-\mathrm{O}-\mathrm{N}$ entities with a similar probability for $T \leq 1600 \mathrm{~K}$, but favors the formation of Si-O-C entities at higher temperatures.

The time evolution of potential energy at various temperatures reveals the dependence of rate and degree of thermal decomposition on the system temperature. For normal nitramine explosives (such as HMX, TATB, RDX), ${ }^{25,27}$ the total potential energy increases initially in the endothermic process of molecule breakdown until the secondary reactions are initiated in the partially decomposed solid material, which begins to release energy due to the exothermic formation of small molecules. Transition to the energy-releasing state follows after reaching the maximum of the potential energy during the endothermic stage of the decomposition, and it happens earlier at more elevated temperatures. These are reflected totally in PETN; however, a significant difference in the potential energy profile of Si-PETN is observed as shown in Fig. 5. The energy remains almost unchanged or even decreases in the initial stage, and it begins to go down dramatically at an earlier time and at a higher rate in the second stage for Si-PETN than for PETN.

At $1200 \mathrm{~K}$, potential energy decreases slightly for Si-PETN with an obvious energy release after $70 \mathrm{ps,} \mathrm{whereas} \mathrm{it} \mathrm{remains}$ almost unchanged for PETN even after 100 ps. At this temperature, the primary initial decomposition mechanism for Si-PETN is $\mathrm{Si}-\mathrm{O}$ bond formation accompanied by a large energy release. Although some endothermic reactions occur later, the quantities of their products are smaller than $\mathrm{Si}-\mathrm{O}$ bonds. Consequently, the total effect is the release of energy, leading to the decrease of potential energy. In the case of PETN, the decomposition process at this temperature is extremely slow with a small number of $\mathrm{O}-\mathrm{NO}_{2}$ bond breaking that absorb energy after $50 \mathrm{ps}$. Therefore, potential energy keeps almost stable. At $1600 \mathrm{~K}$, potential energy keeps almost unchanged within the first $10 \mathrm{ps}$ and then goes down dramatically for Si-PETN, while it increases 

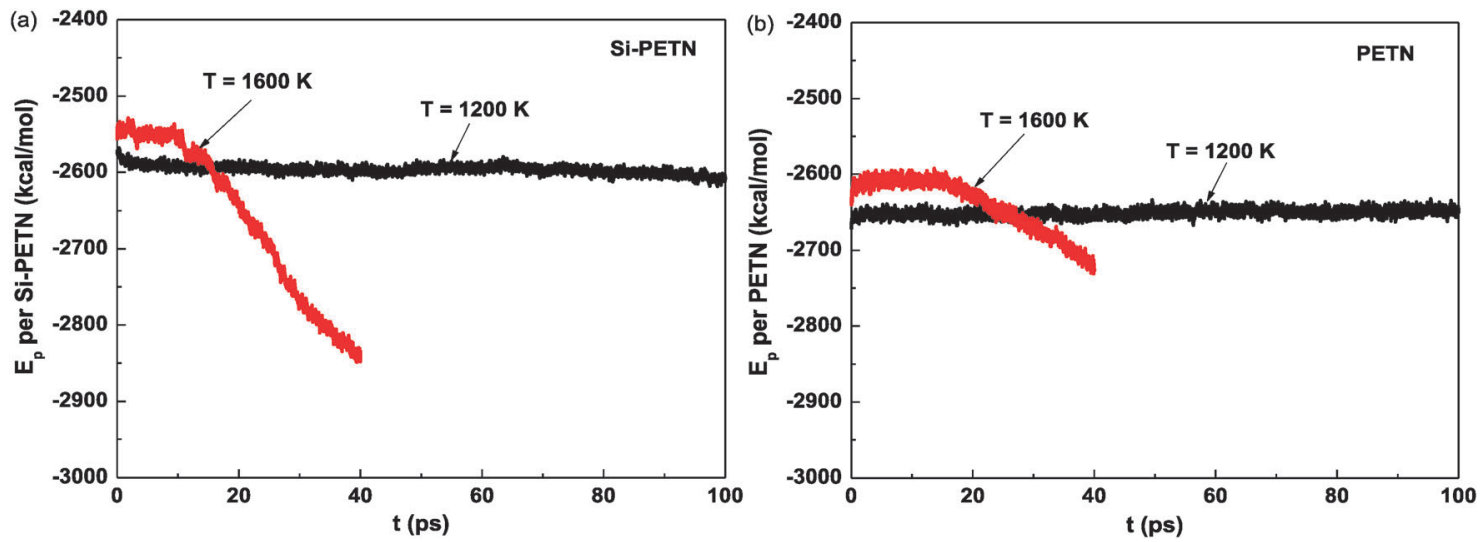

Fig. 5 Potential energy profile during NVT-RMD simulations of Si-PETN and PETN at $1200 \mathrm{~K}$ and $1600 \mathrm{~K}$. It shows a faster energy release for Si-PETN compared with PETN.

from the beginning and starts to decrease after reaching the maximum at about 16 ps for PETN. At this temperature, Si-O bond formation and $\mathrm{O}-\mathrm{NO}_{2}$ bond cleavage are the dominant initial reaction pathways for Si-PETN, releasing $40.5 \mathrm{kcal} \mathrm{mol}^{-1}$ and absorbing $35.6 \mathrm{kcal} \mathrm{mol}^{-1}$ energy, ${ }^{19}$ respectively, leading to a slight decrease of potential energy in the first stage. The decomposition of PETN is initiated by endothermic $\mathrm{O}-\mathrm{NO}_{2}$ bond breaking (39.0 kcal mol${ }^{-1}$ (ref. 19)), resulting in the increase of potential energy. Potential energy decreases as decomposition proceeds, the rate of which is directly related to the progress of exothermic reactions. Since more drastic reactions occur for Si-PETN than for PETN during this stage, more energy is released at a higher rate for Si-PETN, elucidating its highly increased sensitivity. Thus, the difference in the potential energy between Si-PETN and PETN has arisen from the early occurrence of the exothermic Liu Si-C-O rearrangement in Si-PETN, which provides energy early in the decomposition process that accelerates subsequent reactions, leading to earlier and faster energy release for Si-PETN compared with PETN.

To analyze the thermal decomposition reaction kinetics, we focused on two critical reaction pathways: the Liu Si-C-O rearrangement forming $\mathrm{Si}-\mathrm{O}$ bonds and the bond rupture of $\mathrm{O}-\mathrm{NO}_{2}$ to dissociate $\mathrm{NO}_{2}$. The time evolution of the $\mathrm{Si}-\mathrm{O}$ bond and the free $\mathrm{NO}_{2}$ molecule taken from NVT-RMD simulations at temperatures from 1200 to $1800 \mathrm{~K}$ was used to obtain the reaction rate $k$. The data used to obtain the $\mathrm{NO}_{2}$ dissociation rate were from the beginning to the point at which its quantity reaches the maximum and the data for $\mathrm{Si}-\mathrm{O}$ bond formation throughout the whole simulation time were used. The reaction rate was obtained from an exponential fit of the data sets described above at each temperature. Fig. 6 presents the logarithm of the reaction rate as a function of reciprocal temperature, including the linear fitting according to the Arrhenius law to obtain the activation barrier $E_{\mathrm{a}}$ and the pre-exponential factor $A$ :

$$
\ln k=-\frac{E_{\mathrm{a}}}{R T}+\ln A
$$

The derived activation barriers for $\mathrm{Si}-\mathrm{O}$ bond formation and $\mathrm{NO}_{2}$ dissociation in solid Si-PETN are 23.59 and $30.56 \mathrm{kcal} \mathrm{mol}^{-1}$

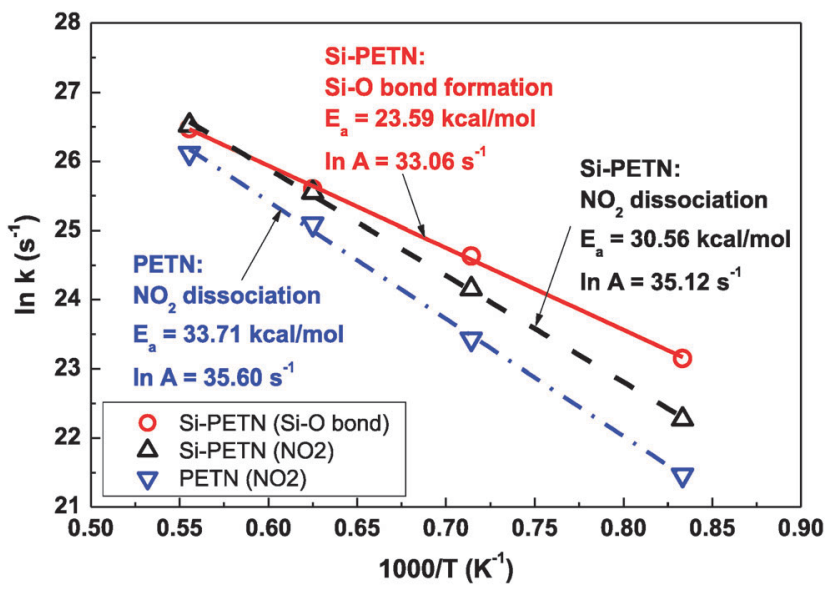

Fig. 6 Logarithm of reaction rates ( $\ln k$ ) for $\mathrm{Si}-\mathrm{O}$ bond formation (red circles) and $\mathrm{NO}_{2}$ dissociation (black up triangles) in Si-PETN along with the rate for $\mathrm{NO}_{2}$ detachment in PETN (blue down triangles) vs. inverse temperature $(1 / T)$ based on NVT-RMD simulations in the temperature range of 1200-1800 K. The corresponding lines passing through these data are results fit to eqn (2). The activation barrier for $\mathrm{Si}-\mathrm{O}$ bond formation is $\sim 7 \mathrm{kcal} \mathrm{mol}^{-1}$ lower than that for $\mathrm{NO}_{2}$ dissociation, confirming that the $\mathrm{Liu} \mathrm{Si}-\mathrm{C}-\mathrm{O}$ rearrangement of $\mathrm{Si}-\mathrm{PETN}$ is more favorable than $\mathrm{O}-\mathrm{NO}_{2}$ bond cleavage.

compared to 32.0 and $35.6 \mathrm{kcal} \mathrm{mol}^{-1}$ from QM studies ${ }^{19}$ on the gas phase, respectively. Table 1 shows that ReaxFF underestimates the barrier for $\mathrm{Si}-\mathrm{O}$ bond formation in an isolated molecule by $\sim 9 \mathrm{kcal} \mathrm{mol}^{-1}$ compared with the QM result, and such energy differences would affect the dynamics of reactions for bulk Si-PETN in the MD simulations, resulting in a lower barrier. ReaxFF predicts a close barrier for $\mathrm{NO}_{2}$ dissociation to QM data in the gas phase, but the barrier decreases in the solid phase. This can be explained by the earlier reaction of $\mathrm{Si}-\mathrm{O}$ bond formation accompanied by a huge energy release, which promotes $\mathrm{O}-\mathrm{NO}_{2}$ bond cleavage. The activation barrier for $\mathrm{Si}-\mathrm{O}$ bond formation is $\sim 7 \mathrm{kcal} \mathrm{mol}^{-1}$ lower than that for $\mathrm{NO}_{2}$ dissociation, confirming that the $\mathrm{Liu} \mathrm{Si}-\mathrm{C}-\mathrm{O}$ rearrangement of Si-PETN is more favorable than $\mathrm{NO}_{2}$ split off. Similar NVT-RMD studies on bulk PETN led to a barrier of $33.71 \mathrm{kcal} \mathrm{mol}^{-1}$ for $\mathrm{NO}_{2}$ 

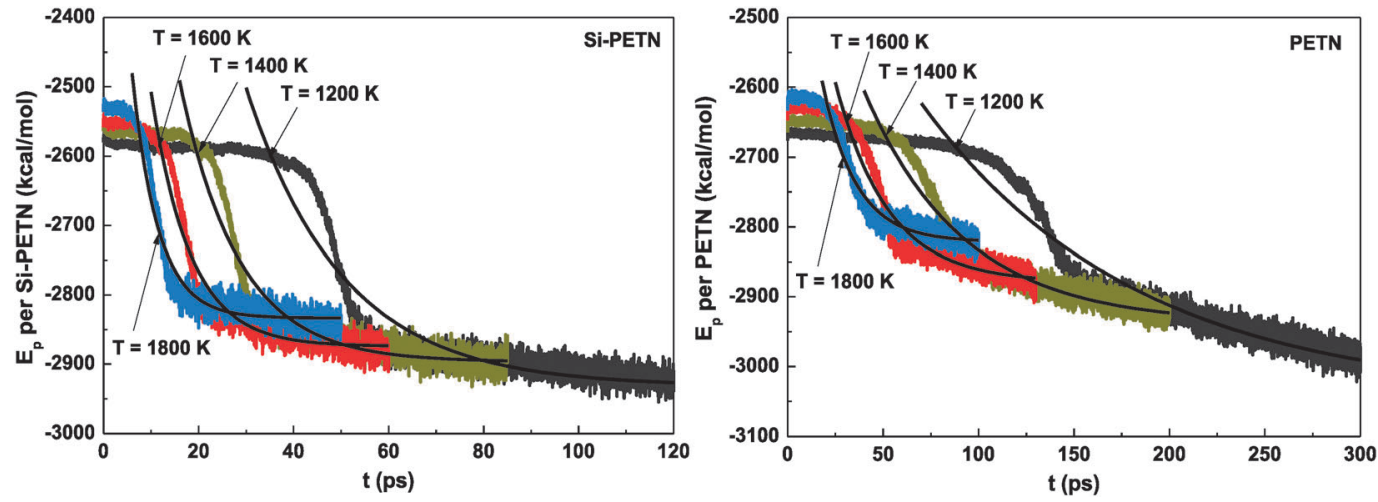

Fig. 7 Potential energy as a function of time during NVE-RMD simulations of Si-PETN and PETN at various temperatures. The black lines are fits of the exothermic stage to eqn (3), which suggest a higher rate for energy release in Si-PETN.

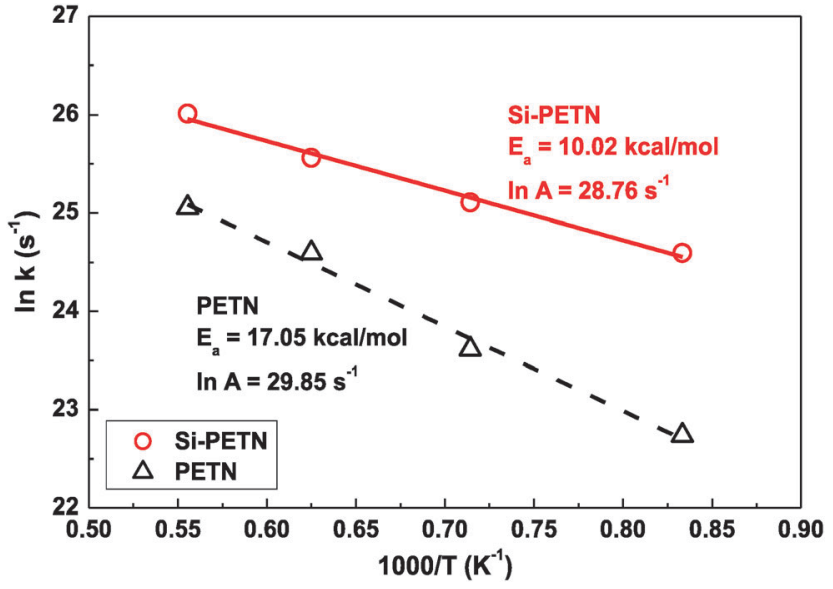

Fig. 8 Logarithm of the exothermic reaction rate $(\ln k)$ vs. inverse temperature $(1 / T)$ during NVE-RMD simulations of Si-PETN and PETN in the 1200-1800 K range. The open circles and the solid line represent calculated values and linear fitting for Si-PETN, and the open triangle and the dashed line represent those for PETN. The figure reveals a higher reaction rate and a lower activation energy for Si-PETN than for PETN.

fission, which is higher than that for Si-PETN. In addition, the huge amount of energy released by $\mathrm{Si}-\mathrm{O}$ bond formation in Si-PETN is sufficient to trigger the following $\mathrm{NO}_{2}$ dissociation, resulting in a higher reaction rate than that for PETN as shown in Fig. 6, making Si-PETN more sensitive than PETN.

The calculated barrier for $\mathrm{NO}_{2}$ loss in PETN of $34 \mathrm{kcal} \mathrm{mol}^{-1}$ is lower than the values extracted from fits of models to experimental results $\left(40 \mathrm{kcal} \mathrm{mol}^{-1}\right.$ from Tarver et al. ${ }^{9}$ and $47 \mathrm{kcal} \mathrm{mol}^{-1}$ from Rogers et al. ${ }^{6,7}$ ). However, caution must be exercised when comparing calculated kinetics based on atomistic details of molecular transformation with those extracted using empirical models based on "ignition times". Tarver $e t a l . .^{9}$ developed a four-step chemical kinetic model for the thermal decomposition of PETN based on time to thermal explosion measured in a new one dimensional time to explosion (ODTX) apparatus. The kinetic parameters of the model were fitted to reproduce the ODTX in experiments. Rogers et $a l^{6,7}$ estimated the kinetic parameters from calorimetry experiments near the melting temperature of PETN. Our ReaxFF RMD yields reaction rates for temperatures of 1200$1800 \mathrm{~K}$, while most of the experimental data were obtained at temperatures below $\sim 500 \mathrm{~K}$, requiring extrapolation of the measured rates to much higher temperatures. We can expect that additional reaction channels and autocatalytic processes in the solid phase may be activated at higher temperatures that might invalidate such extrapolations. Moreover, the experimental measurements are done on substantially larger samples
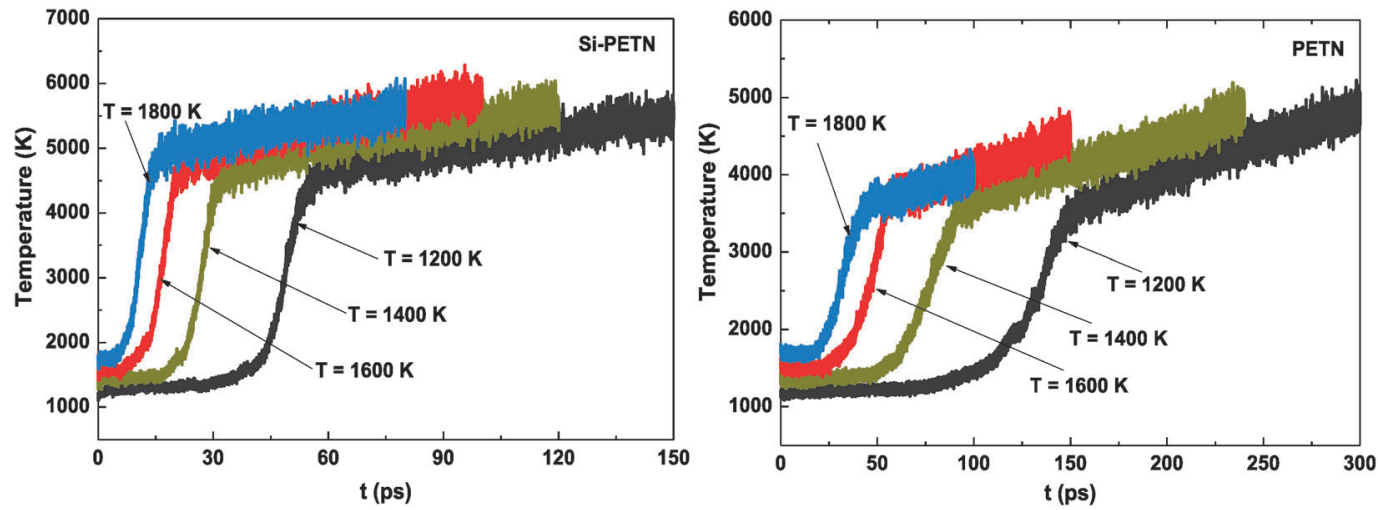

Fig. 9 Temperature as a function of time during NVE-RMD simulations of Si-PETN and PETN. It is shown that the temperature rises to a higher value in a shorter time for Si-PETN compared with PETN. 

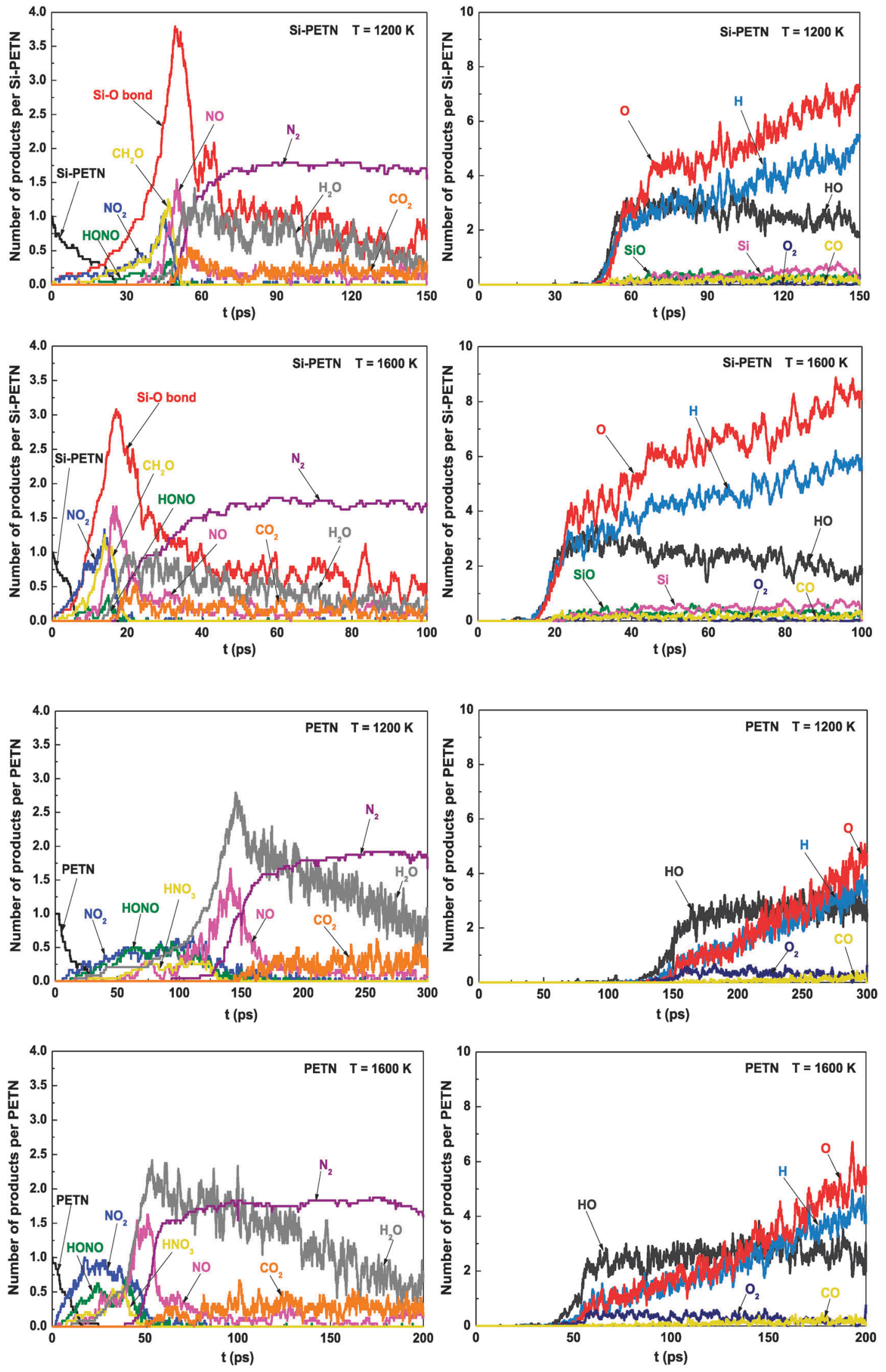

Fig. 10 Time evolution of products during NVE-RMD simulations of Si-PETN and PETN at 1200 and $1600 \mathrm{~K}$. 
involving a nonhomogeneous reacting medium in which significant mass and heat flow may occur. Thus due to the heterogeneity (e.g. defects, impurity, interfaces) of the material, they provide only indirect and very approximate estimations of the bulk reaction rates. In contrast our simulations deal with a tiny amount of ideal, defect-free material that is quickly heated to a high temperature and then kept at a constant temperature. Additionally, thermal decomposition experiments measure only degradation of aggregate materials without distinguishing between individual reactions. Thus, these factors complicate the comparison of experimental results with ReaxFF reactive dynamics.

3.3.2 NVE-RMD simulations. Within the NVT ensemble, the equations of motion are coupled with a thermostat to regulate the temperature of the system to maintain a target simulation temperature. This will tend to dampen the energy release associated with an exothermic chemical reaction. Instead, this energy release from exothermal reactions would increase the temperature, which might influence the mechanisms and rates. Therefore, we carried out constant volume-constant energy reactive molecular dynamics (NVE-RMD) simulations to obtain the kinetics of energy release, temperature increase, and reaction sequence steps induced by intense heating. Analogous simulations were also carried out for bulk PETN for comparison.

The potential energy profiles for each of the four initial temperatures $(T=1200,1400,1600$, and $1800 \mathrm{~K})$ are shown in Fig. 7. After an initial equilibration and induction time (denoted $t_{0}$ ) the potential energy decreases with time as the chemical reactions progress. The data from $t_{0}$, for each initial temperature, were fit to the exponential function:

$$
U(t)=U_{\infty}+\Delta U\left[\exp \left(\frac{-\left(t-t_{0}\right)}{\tau}\right)\right]
$$

where $U_{\infty}$ is the asymptotic energy of the products, $\Delta U$ is the exothermicity of the reaction, $\tau$ is an overall characteristic time of reaction, and the reaction rate is taken to be $\tau^{-1}$.

The energy releases earlier and faster for Si-PETN, resulting in a shorter induction time along with an $\sim 3$ times higher reaction rate than that for PETN. Fig. 8 shows the rates as a function of temperature that were fitted to Arrhenius law (eqn (2)) to investigate the kinetics of the exothermic stage. The effective activation energy calculated for Si-PETN is $10.02 \mathrm{kcal} \mathrm{mol}^{-1}$, significantly lower than the $17.05 \mathrm{kcal} \mathrm{mol}^{-1}$ for PETN, indicating a lower energy barrier and higher sensitivity for Si-EPTN. The calculated barrier for PETN is lower than the experimental result (30.31 kcal mol${ }^{-1}$ (ref. 9)), which is probably because of the vast difference in the initial temperature range between this study (1200-1800 K) and experiment (400-500 K), the lack of well-defined temperatures due to the use of the microcanonical ensemble, and the large difference in system size and material purity. The potential energy releases much faster with a rapid decreasing stage for NVE-RMD simulation in comparison with that for NVT-RMD simulation showing a gradual decrease.

The huge energy release due to exothermic reactions leads to a large increase in the temperature of the system as shown in Fig. 9. The dramatic rise of temperature begins at the time of steep drop in energy, resulting in extremely high temperature of the system which in turn promotes chemical reactions. The temperature in bulk Si-PETN reaches about $4400 \mathrm{~K}$ at $60 \mathrm{ps}$ for the initial temperature of $1200 \mathrm{~K}, 4400 \mathrm{~K}$ at $34 \mathrm{ps}$ for the initial temperature of $1400 \mathrm{~K}, 4600 \mathrm{~K}$ at $23 \mathrm{ps}$ for the initial temperature of $1600 \mathrm{~K}$, and $5000 \mathrm{~K}$ at $15 \mathrm{ps}$ for the initial temperature of 1800 K. A similar phenomenon is observed for PETN but the temperature rises to about $3500 \mathrm{~K}$ at $153 \mathrm{ps}$ for the initial temperature of $1200 \mathrm{~K}, 3500 \mathrm{~K}$ at $98 \mathrm{ps}$ for the initial temperature of $1400 \mathrm{~K}, 3600 \mathrm{~K}$ at $62 \mathrm{ps}$ for the initial temperature of $1600 \mathrm{~K}$, and $3600 \mathrm{~K}$ at $50 \mathrm{ps}$ for the initial temperature of $1800 \mathrm{~K}$, which is about $1000 \mathrm{~K}$ lower than that in Si-PETN for each case. This much slower increasing rate for PETN in comparison with that for Si-PETN is in accordance with the much slower energy discharge process.

Fig. 10 exhibits the evolution of major products during NVE-RMD simulations. The four initial leading reaction pathways of Si-PETN decomposition found in the NVT-RMD simulations ( $\mathrm{Si}-\mathrm{O}$ bond formation, $\mathrm{O}-\mathrm{NO}_{2}$ bond fission, $\mathrm{CH}_{2} \mathrm{O}$ elimination, and HONO elimination) are also detected during NVE-RMD simulations but at higher reaction rates due to the increase in the temperature of the system starting early in the decomposition process. Secondary exothermic reactions are initiated more quickly after these initial products reaching the maximum, resulting in the formation of various intermediates as well as stable final products, leading to remarkable differences between NVE and NVT results. First, NVE leads to the production of numerous $\mathrm{N}_{2}, \mathrm{HO}, \mathrm{H}$, and $\mathrm{O}$ species, the steep rise of which matches, in time, the steep rise in temperature (Fig. 9) and the steep decline in potential energy (Fig. 7). Moreover, a variety of other final products are formed, such as $\mathrm{CO}_{2}, \mathrm{CO}, \mathrm{SiO}$, and $\mathrm{Si}$, most of which were not observed in the NVT-RMD simulations. In addition, an increased number of $\mathrm{H}_{2} \mathrm{O}$ molecules are formed during NVE-RMD simulations. Thus, the increase in temperature does not change the initial decomposition mechanisms but it certainly accelerates the initial reaction process and significantly influences the secondary exothermic reaction mechanisms and rate. The main decomposition species in PETN are also plotted in this figure for comparison, showing that the decomposition process of PETN proceeds much more tardily that leads to a slower energy release as well as temperature increase than that for Si-PETN, which is the same as that from NVT-RMD simulations.

We have to stress that during these NVT and NVE-RMD simulations, the pressure is building up within the system because of exothermic reactions. For NVT-RMD simulations, the pressure begins to increase gradually in the vicinity of the time where the potential energy starts to decrease; for NVE-RMD simulations, the pressure shows a rapid increasing stage, which matches in time with the fast energy release. The increase in pressure may influence the kinetic parameters extracted from these MD simulations, which was not addressed in this work.

\section{Summary and conclusions}

To permit reaction simulations to determine the nature of sensitivity in bulk samples of Si-PETN, an extremely sensitive 
explosive, we extended the ReaxFF reactive force field to treat this system by means of training with a suite of data derived from QM calculations on molecules relevant to Si-PETN chemistry. The predicted molecular and crystal structures by this force field are in good agreement with those from QM calculations, validating that this force field is suitable for Si-PETN.

The reaction mechanisms and kinetics of the thermal decomposition process in bulk Si-PETN at constant temperatures are revealed by NVT-RMD simulations. The dominant initial reaction pathway at lower temperatures $(T \leq 1200 \mathrm{~K})$ is the Liu carbon-silyl nitro-ester rearrangement of $\mathrm{Si}-\mathrm{C}-\mathrm{O}$ to form $\mathrm{Si}-\mathrm{O}$ bonds accompanied by a large energy release, which promotes $\mathrm{NO}_{2}$ dissociation from $\mathrm{N}-\mathrm{OC}$ bond cleavage. The $\mathrm{Si}-\mathrm{O}$ bond formation reaction remains as a predominant initial step at higher temperatures where remarkably increased $\mathrm{NO}_{2}$ dissociation and $\mathrm{CH}_{2} \mathrm{O}$ and HONO elimination occur. The derived activation barrier is $23.59 \mathrm{kcal} \mathrm{mol}^{-1}$ for $\mathrm{Si}-\mathrm{O}$ bond formation and is $30.56 \mathrm{kcal} \mathrm{mol}^{-1}$ for $\mathrm{NO}_{2}$ splitting. The key here is that while the $\mathrm{O}-\mathrm{NO}_{2}$ bond breaking and the $\mathrm{Si}-\mathrm{O}$ bond formation reactions co-exist in Si-PETN decomposition, the formation of $\mathrm{Si}-\mathrm{O}$ bonds has a low energy barrier and is autocatalytic and thus is more favorable.

To consider the temperature increase of materials induced by energy release during thermal decomposition, additional NVERMD simulations are carried out. The results manifest that during the exothermic stage temperature goes up to a very high value within a very short span, the steep rise of which matches, in time, the steep drop in energy and the dramatic increase in final products. The increase in temperature does not change the initial decomposition mechanisms but indeed accelerates the initial reaction process and significantly influences the secondary exothermic reaction mechanisms and rate. In comparison with PETN, the reaction rate for the exothermic stage in Si-PETN is $\sim 3$ times higher and the activation energy is $\sim 7 \mathrm{kcal} \mathrm{mol}^{-1}$ lower, demonstrating the higher sensitivity of Si-PETN.

Finally, we come to the reasons for the significantly increased sensitivity of Si-PETN. Firstly, the Liu carbon-silyl nitro-ester rearrangement leads to a lower barrier than any of the normal PETN decomposition mechanisms, initiating reactions at lower temperature. Secondly, the exothermicity of the $\mathrm{Si}-\mathrm{O}$ bond formation provides huge energy early in the decomposition process to promote further decomposition, whereas the initial steps are endothermic in PETN. It must be emphasized that for both the Si-PETN molecule and the Si-PETN crystal, it is the intramolecular rearrangement of $\mathrm{Si}-\mathrm{O}$ bonds that determines the colossal sensitivity.

\section{Acknowledgements}

This work was supported by the US Army Research Office (W911NF-05-1-0345 and W911NF-08-1-0124; Ralph Anthenien program manager) and by the Office of Naval Research (N00014-09-1-0634; Cliff Bedford program manager). It was also supported by the National Natural Science Foundation of China (Grant No. 11172044 and 11402031).

\section{Notes and references}

1 T. J. Dunn, W. L. Neumann, M. M. Rogic and S. R. Woulfe, Versatile methods for the synthesis of differentially functionalized pentaerythritol amine derivatives, J. Org. Chem., 1990, 55, 6368-6373.

2 J. Köhler and R. Meyer, Explosive, Wiley-VCH, Weinheim, Germany, 9th edn, 1998.

3 W. S. Anderson, H. J. Hyer, I. E. Sundberg and T. P. Rudy, Pentaerythrityltetramine, Ind. Eng. Chem. Res., 2000, 39, 4011-4013.

4 H. H. Cady and A. C. Larson, Pentaerythritol tetranitrate II: its crystal structure and transformation to PETN I; an algorithm for refinement of crystal structures with poor data, Acta Crystallogr., Sect. B: Struct. Crystallogr. Cryst. Chem., 1975, 31, 1864-1869.

5 O. Tschauner, B. Kiefer, Y. Lee, M. Pravica, M. Nicol and E. J. Kim, Structural transition of PETN-I to ferroelastic orthorhombic phase PETN-III at elevated pressure, J. Chem. Phys., 2007, 127, 094502.

6 R. N. Rogers, Thermochemistry of explosives, Thermochim. Acta, 1975, 11, 131-139.

7 R. N. Rogers, J. L. Janney and M. H. Ebinger, Kinetic-isotope effects in thermal explosives, Thermochim. Acta, 1982, 59, 287-298.

8 W. L. Ng, J. E. Field and H. M. Hauser, Thermal, fracture, and laser-induced decomposition of pentaerythritol tetranitrate, J. Appl. Physiol., 1986, 59, 3945.

9 C. M. Tarver, T. D. Tran and R. E. Whipple, Thermal decomposition of pentaerythritol tetranitrate, Propellants, Explos., Pyrotech., 2003, 28, 189-193.

10 M. Conroy, L. I. Oleynik, S. V. Zybin and C. T. White, Firstprinciples investigation of anisotropic constitute relationship in pentaerythritol tetranitrate, Phys. Rev. B: Condens. Matter Mater. Phys., 2008, 77, 094107.

11 M. A. Hiskey, K. R. Brower and J. C. Oxley, Thermal decomposition of nitrate esters, J. Phys. Chem., 1991, 95, 3955-3960.

12 Y. A. Gruzdkov and Y. M. Gupta, Shock Wave Initiation of Pentaerythritol Tetranitrate Single Crystals: Mechanism of Anisotropic Sensitivity, J. Phys. Chem. A, 2000, 104, 11169-11176.

13 Y. A. Gruzdkov and Y. M. Gupta, Vibrational Properties and Structure of Pentaerythritol Tetranitrate, J. Phys. Chem. A, 2001, 105, 6197-6202.

14 Y. A. Gruzdkov, Z. A. Dreger and Y. M. Gupta, Experimental and Theoretical Study of Pentaerythritol Tetranitrate Conformers, J. Phys. Chem. A, 2004, 108, 6216-6221.

15 I. V. Schweigert and B. I. Dunlap, Electronic structure and molecular dynamics of breaking the $\mathrm{RO}-\mathrm{NO}_{2}$ bond, J. Chem. Phys., 2009, 130, 244110.

16 S. V. Zybin, W. A. Goddard III, P. Xu, A. C. T. van Duin and A. P. Thompson, Physical mechanism of anisotropic sensitivity in pentaerythritol tetranitrate from compressive-shear reaction dynamics simulations, Appl. Phys. Lett., 2010, 96, 081918. 
17 T. R. Gibbs and A. Popolato, LASL explosive property data, University of California Press, Berkeley, US, 1980.

18 T. M. Klapötke, B. Krumm, R. Ilg, D. Troegel and R. Tacke, The Sila-Explosives $\mathrm{Si}\left(\mathrm{CH}_{2} \mathrm{~N}_{3}\right)_{4}$ and $\mathrm{Si}\left(\mathrm{CH}_{2} \mathrm{ONO}_{2}\right)_{4}$ : Silicon Analogues of the Common Explosives Pentaerythrityl Tetraazide, $\mathrm{C}\left(\mathrm{CH}_{2} \mathrm{~N}_{3}\right)_{4}$, and Pentaerythritol Tetranitrate, $\mathrm{C}\left(\mathrm{CH}_{2} \mathrm{ONO}_{2}\right)_{4}$, J. Am. Chem. Soc., 2007, 129, 6908-6915.

19 W. G. Liu, S. V. Zybin, S. Dasgupta, T. M. Klapötke and W. A. Goddard III, Explanation of the Colossal Detonation Sensitivity of Silicon Pentaerythritol Tetranitrate (Si-PETN) Explosive, J. Am. Chem. Soc., 2009, 131, 7490-7491.

20 J. S. Murray, P. Lane, A. Nieder, T. M. Klapötke and P. Politzer, Enhanced detonation sensitivities of silicon analogs of PETN: reaction force analysis and the role of $\sigma$-hole interactions, Theor. Chem. Acc., 2010, 127, 345-354.

21 Y. Lin, M. M. Budzevich, A. C. Landerville, I. I. Oleynik and C. T. White, Physical and chemical properties of a new energetic materials SiPETN, AIP Conf. Proc., 2009, 1195, 474-477.

22 A. C. T. van Duin, S. Dasgupta, F. Lorant and W. A. Goddard III, ReaxFF: A Reactive Force Field for Hydrocarbons, J. Phys. Chem. A, 2001, 105, 9396-9409.

23 A. C. T. van Duin, A. Strachan, S. Stewman, Q. Zhang, X. Xu

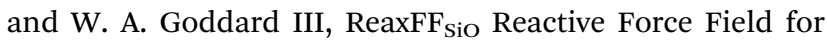
Silicon and Silicon Oxide Systems, J. Phys. Chem. A, 2003, 107, 3803-3811.

24 T. T. Zhou, S. V. Zybin, Y. Liu, F. L. Huang and W. A. Goddard III, Anisotropic shock sensitivity for $\beta$-octahydro-1,3,5,7-tetranitro-1,3,5,7-tetrazocine energetic material under compressive-shear loading from ReaxFF-lg reactive dynamics simulations, J. Appl. Physiol., 2012, 111, 124904.

25 L. Z. Zhang, S. V. Zybin, A. C. T. van Duin, S. Dasgupta and W. A. Goddard III, Carbon Cluster Formation during Thermal Decomposition of Octahydro-1,3,5,7-tetranitro-1,3,5,7-tetrazocine and 1,3,5-triamino-2,4,6-trinitrobenzene High Explosives from ReaxFF Reactive Molecular Dynamics Simulations, J. Phys. Chem. A, 2009, 113, 10619-10640.

26 T. T. Zhou and F. L. Huang, Effects of Defects on Thermal Decomposition of HMX via ReaxFF Molecular Dynamics Simulations, J. Phys. Chem. B, 2011, 115, 278-287.

27 A. Strachan, E. Kober, A. C. T. van Duin, J. Oxgaard and W. A. Goddard III, Thermal Decomposition of RDX from reactive dynamics, J. Chem. Phys., 2005, 122, 054502.

28 A. Strachan, A. C. T. van Duin, D. Chakraborty, S. Dasgupta and W. A. Goddard III, Shock Waves in High-Energy Materials: The Initial Chemistry Events in Nitramine RDX, Phys. Rev. Lett., 2003, 91, 098301.

29 K. Nomura, R. K. Kalia, A. Nakano, P. Vashishta, A. C. T. van Duin and W. A. Goddard III, Dynamic Transition in the Structure of an Energetic Crystal during Chemical Reactions at Shock Front Prior to Detonation, Phys. Rev. Lett., 2007, 99, 148303.
30 K. Nomura, R. K. Kalia, A. Nakano and P. Vashishta, Reactive nanojets: Nanostructure-enhanced chemical reactions in a defected energetic crystal, Appl. Phys. Lett., 2007, 91, 183109.

31 Q. An, S. V. Zybin, W. A. Goddard III, A. Jaramillo-Botero, M. Blanco and S. N. Luo, Elucidation of the Dynamics for Hot-spot Initiation at Nonuniform Interfaces of Highly Shocked Materials, Phys. Rev. B: Condens. Matter Mater. Phys., 2011, 84, 220101.

$32 \mathrm{~J}$. Tersoff, New empirical approach for the structure and energy of covalent systems, Phys. Rev. B: Condens. Matter Mater. Phys., 1988, 37, 6991-7000.

33 D. W. Brenner, Empirical potential for hydrocarbons for use in simulating the chemical vapor decomposition of diamond films, Phys. Rev. B: Condens. Matter Mater. Phys., 1990, 42, 9458-9471.

34 L. C. Liu, Y. Liu, S. V. Zybin, H. Sun and W. A. Goddard III, ReaxFF-lg: Correction of the ReaxFF Reactive Force Field for London Dispersion with Applications to the Equations of State for Energetic Materials, J. Phys. Chem. A, 2011, 115, 11016-11022.

35 K. Chenoweth, S. Cheung, A. C. T. van Duin, W. A. Goddard III and E. M. Kober, Simulations on the Thermal Decomposition of a Poly(dimethylsiloxane) Polymer Using the ReaxFF Reactive Force Field, J. Am. Chem. Soc., 2005, 127, 7192-7202.

36 A. D. Becke, Density-functional thermochemistry. III. The role of exact exchange, J. Chem. Phys., 1993, 98, 5648.

37 C. T. Lee, W. T. Yang and R. G. Parr, Development of the Colle-Salvetti correlation-energy formula into a functional of the electron density, Phys. Rev. B: Condens. Matter Mater. Phys., 1988, 37, 785-789.

38 R. Krishnan, J. S. Binkley, R. Seeger and J. A. Pople, Selfconsistent molecular orbital methods. XX. A basis set for correlated functions, J. Chem. Phys., 1980, 72, 650.

39 Jaguar, Schrödinger, LLC, New York, 7.5 edn, 2008.

40 J. W. Conant, H. H. Cady, R. R. Ryan, J. L. Yarnell and J. M. Newsam, Informal Report LA-7756-MS, Los Alamos National Laboratory, Los Alamos, NM, 1979.

41 A. D. Booth and F. J. Llewellyn, The crystal structure of pentaerythritol tetranitrate, J. Chem. Soc., 1947, 837-846.

42 D. F. Shanno, Conjugate Gradient Methods with Inexact Searches, Math. Oper. Res., 1978, 3, 244-256.

43 S. J. Plimpton, Fast Parallel Algorithm for Short-Range Molecular Dynamics, Comput. Phys., 1995, 117, 1-19.

44 Q. An, Y. Liu, S. V. Zybin, H. Kim and W. A. Goddard III, Anisotropic Shock Sensitivity of Cyclotrimethylene Trinitramine (RDX) from Compress and Shear Reactive Dynamics, J. Phys. Chem. C, 2012, 116, 10198-10206.

45 M. A. Neumann and M. A. Perrin, Energy Ranking of Molecular Crystal Using Density Functional Theory Calculations and an Empirical van der Waals Correction, J. Phys. Chem. B, 2005, 109, 15531-15541. 